\title{
Citrate-mediated iron uptake in Pseudomonas aeruginosa: involvement of the citrate-inducible FecA receptor and the FeoB ferrous iron transporter
}

Correspondence

Keith Poole

poolek@queensu.ca

Received 20 August 2008

Revised 17 September 2008

Accepted 19 September 2008
Bryan Marshall, ${ }^{1}$ Alain Stintzi, ${ }^{2}$ Christie Gilmour, ${ }^{1}$ Jean-Marie Meyer $^{3}$ and Keith Poole

\author{
${ }^{1}$ Department of Microbiology and Immunology, Queen's University, Kingston, Ontario K7L 3N6, \\ Canada \\ ${ }^{2}$ Ottawa Institute of Systems Biology, Department of Biochemistry, Microbiology and Immunology, \\ University of Ottawa, Ottawa, Ontario K1H 8M5, Canada \\ ${ }^{3}$ Laboratoire de Microbiologie et Génétique, Université Louis Pasteur/CNRS FRE 2326, 28 rue \\ Goethe, 67083 Strasbourg, France
}

In an attempt to identify components of a ferric citrate uptake system in Pseudomonas aeruginosa, a mutant library of a siderophore-deficient strain (IA614) was constructed and screened for defects in citrate-promoted growth in an Fe-restricted medium. A mutant disrupted in gene PA3901, encoding a homologue of the outer-membrane ferric citrate receptor, FecA, of Escherichia coli $\left(\mathrm{FecA}_{\mathrm{E} . \mathrm{c} .}\right)$, was recovered and shown to be deficient in citrate-promoted growth and citrate-mediated Fe uptake. A mutant disrupted in gene PA4825, encoding a homologue of the MgtA/MgtB $\mathrm{Mg}^{2+}$ transporters in Salmonella enterica, was similarly deficient in citratepromoted growth, though this was due to a citrate sensitivity of the mutant apparently resulting from citrate-promoted acquisition of $\mathrm{Fe}^{2+}$ and resultant oxidative stress. Consistent with citrate delivering $\mathrm{Fe}$ to cells as $\mathrm{Fe}^{2+}$, a $P$. aeruginosa mutant lacking the $\mathrm{FeoB} \mathrm{Fe}^{2+}$ transporter homologue, PA4358, was compromised for citrate-promoted growth in Fe-restricted medium and showed markedly reduced citrate-mediated Fe uptake. Subsequent elimination of two $\mathrm{Fe}^{3+}$ transporter homologues, PA5216 and PA4687, in the feoB mutant failed to further compromise citrate-promoted growth or Fe uptake, though the additional loss of $p c o A$, encoding a periplasmic ferroxidase implicated in $\mathrm{Fe}^{2+}$ acquisition, completely abrogated citrate-mediated $\mathrm{Fe}$ uptake. $\mathrm{Fe}$ acquisition mediated by other siderophores (e.g. pyoverdine) was, however, unaffected in the quadruple knockout strain. These data indicate that Fe delivered to $P$. aeruginosa by citrate is released as $\mathrm{Fe}^{2+}$, probably in the periplasm, prior to its transport into cells via Fe transport components.

\section{INTRODUCTION}

Iron is an essential nutrient whose acquisition by Pseudomonas aeruginosa is often facilitated by high-affinity iron-chelating molecules termed siderophores that, together with cell-surface receptors specific for the ironsiderophore complexes, serve to provide the organism with iron under the most nutritionally dilute conditions (Poole \& McKay, 2003). P. aeruginosa produces two siderophores,

Abbreviations: ECF, extracytoplasmic function; EDDA, ethylenediaminediacetic acid; EDDHA, ethylenediaminedi(o-hydroxyphenylacetic) acid.

Supplementary material with details of primers and cycling parameters for construction of deletion mutants is available with the online version of this paper. pyoverdine (Meyer \& Hornsperger, 1978; Poole et al., 1991; Poole \& McKay, 2003; Visca et al., 2007) and pyochelin (Ankenbauer et al., 1988; Heinrichs et al., 1991; Poole \& McKay, 2003), though the organism is also able to utilize several siderophores produced by fungi and other bacteria (Cornelis et al., 1987; Cuiv et al., 2006, 2007; Llamas et al., 2006, 2008; Meyer, 1992; Meyer et al., 1999; Poole et al., 1990), as well as additional molecules with Fe-chelating ability [e.g. citrate (Cox, 1980b; Harding \& Royt, 1990)]. While outer-membrane receptors for most of these heterologous siderophores have been identified (Banin et al., 2005; Cuiv et al., 2006; Ghysels et al., 2005; Llamas et al., 2006, 2008; Poole et al., 1990), additional (e.g. periplasmic or inner-membrane) transport components 
are generally not evident from the genome sequence. This is in contrast to siderophore transport systems in Escherichia coli (Braun, 2003) and the pyochelin transport system in P. aeruginosa (Michel et al., 2007), where siderophore-specific post-outer-membrane transporters have been identified. Homologues of the fepBCG genes associated with ferric enterobactin uptake across the periplasm and inner membrane of E. coli are, however, present in the $P$. aeruginosa genome (Poole \& McKay, 2003) though an involvement in ferric enterobactin uptake has not been examined. Receptor genes for heterologous siderophores in $P$. aeruginosa are often only linked to genes encoding an extracytoplasmic function (ECF) sigma factor and cognate anti-sigma factor (Poole \& McKay, 2003; Visca et al., 2002) implicated in siderophore-dependent induction of receptor gene expression (Llamas et al., 2006, 2008). This is presumably to ensure that these receptors are only synthesized when the cognate siderophore is available. $P$. aeruginosa may, thus, possess a common post-outermembrane uptake system for Fe delivered to the organism via various heterologous siderophores and their receptors. Homologues of inner-membrane permeases for $\mathrm{Fe}^{3+}$ and $\mathrm{Fe}^{2+}$ have, for example, been described in P. aeruginosa (Poole \& McKay, 2003), where they could function in trans-cytoplasmic membrane transport of $\mathrm{Fe}^{3+}$ or $\mathrm{Fe}^{2+}$ delivered to the periplasm by siderophores and their receptors.

A homologue of the $f e c A$ gene encoding a ferric citrate receptor in E. coli, PA3901, has been identified in $P$. aeruginosa (Poole \& McKay, 2003; Visca et al., 2002), and citrate-dependent binding of $\mathrm{Fe}$ to isolated outer membranes has been seen (Harding \& Royt, 1990), consistent with the presence of a ferric citrate receptor in this organism. In E. coli, fecA and additional transport genes responsible for delivery of ferric citrate to the cytoplasm are specifically induced under Fe-limiting conditions in the presence of exogenous citrate (Braun, 2003). This is mediated by FecA in conjunction with the FecR sensor/ anti-sigma factor and FecI ECF sigma factor, which collectively sense ferric citrate in the environment and activate $f e c$ transport gene expression (Braun \& Mahren, 2005; Braun et al., 2006; Visca et al., 2002). P. aeruginosa $f e c A$ is linked to homologues of the E. coli fecI (PA3899) and $f e c R$ (PA3900) genes (Poole \& McKay, 2003), though additional $f e c$ transport homologues are not identifiable in $P$. aeruginosa. While the citrate inducibility of PA3901 has not been examined, the ferric citrate-binding activity of isolated $P$. aeruginosa outer membranes is dependent upon growth in low-Fe citrate-containing medium (Harding \& Royt, 1990), and PA3901/PA3900-3899 are inducible by Fe limitation (Ochsner et al., 2002). Moreover, citratepromoted biofilm formation in PA3901 ${ }^{+}$but not PA3901 P. aeruginosa (Banin et al., 2005) is consistent with PA3901's annotated function as the ferric citrate receptor. The current study was undertaken to confirm FecA's presumed function in ferric citrate uptake and to identify constituents involved in post-outer-membrane transport of
Fe delivered to $P$. aeruginosa by citrate, as a model of heterologous siderophore uptake where siderophore-specific post-outer-membrane transport components are not evident.

\section{METHODS}

Bacterial strains and growth media. Bacterial strains and plasmids used in this study are listed in Table 1 . Bacteria were cultivated at $37{ }^{\circ} \mathrm{C}$ in Luria (L) broth as before (Nehme et al., 2004) supplemented with antibiotics to maintain plasmids as needed [pEX18Tc, pRK415 and their derivatives: tetracycline $\left(10 \mu \mathrm{g} \mathrm{ml}^{-1}\right.$, E. coli; $75 \mu \mathrm{g} \mathrm{ml}^{-1}, P$. aeruginosa); pK18MobSacB and its derivatives: kanamycin $(50 \mu \mathrm{g}$ $\mathrm{ml}^{-1}$, E. coli; $1500 \mu \mathrm{g} \mathrm{ml} \mathrm{g}^{-1}$, P. aeruginosa); $\mathrm{pUCP} 18$ and its derivatives: ampicillin $\left(100 \mu \mathrm{g} \mathrm{ml} \mathrm{m}^{-1}, E\right.$. coli) or carbenicillin $\left(800 \mu \mathrm{g} \mathrm{ml} \mathrm{g}^{-1}, \quad P\right.$. aeruginosa); pUT::mini-Tn5-tet: tetracycline $\left(10 \mu \mathrm{g} \mathrm{ml} \mathrm{g}^{-1}\right.$, E. coli); pCR-Blunt II-TOPO: ampicillin $(100 \mu \mathrm{g}$ $\mathrm{ml}^{-1}$, E. coli)]. The iron-limited succinate minimal media [here dubbed 'A' (Meyer \& Abdallah, 1978) and 'B' (Poole et al., 1990)] have been described previously.

DNA techniques. Standard protocols were used for restriction endonuclease digestions, ligations, transformation, preparation of electrocompetent cells and agarose gel electrophoresis, as described by Sambrook \& Russell (2001). Purification of plasmids and PCR products was carried out using the QIAprep Spin Miniprep and QIAquick PCR Purification kits (Qiagen), respectively. Genomic DNA of $P$. aeruginosa was extracted according to the protocol of Barcak et al. (1991). E. coli cells were made competent using the method of Inoue et al. (1990). P. aeruginosa were made electrocompetent by the method described by Choi et al. (2005). DNA sequencing was performed by ACGT Corporation (Toronto, Ontario, Canada) with universal and custom oligonucleotides.

Plasmids. The PA3901 ( $f e c A)$ and PA4825 ( $m g t A)$ genes were cloned into pUCP18 following their amplification (via PCR) from the chromosome of $P$. aeruginosa IA614 and initial cloning into plasmid pCR-Blunt II-TOPO (Invitrogen) to yield plasmids pBM11 and pBM13, respectively. PA3901 was amplified using the primer pair PA3901-For (5' -GAATTCGAATTCCACCTGAGCCTTTTTCCCCAC3'; tandem EcoRI sites underlined)/PA3901-Rev (5'-AAGCTTAAGCTTCTGGCGATCGTCCGCCGTTG-3'; tandem HindIII sites underlined) in a reaction that involved heating at $94{ }^{\circ} \mathrm{C}$ for $3 \mathrm{~min}$ followed by 30 cycles of $15 \mathrm{~s}$ at $94{ }^{\circ} \mathrm{C}, 30 \mathrm{~s}$ at $59{ }^{\circ} \mathrm{C}$ and $3 \mathrm{~min}$ at $68{ }^{\circ} \mathrm{C}$, before finishing with $10 \mathrm{~min}$ at $68{ }^{\circ} \mathrm{C}$. The blunt-ended PA3901-carrying PCR product was purified, cloned into pCR-Blunt II-TOPO according to a protocol provided by the manufacturer, excised from this plasmid via EcoRI/HindIII digestion and subsequently cloned into pUCP18. PA4825 was similarly cloned following amplification with the primer pair PA4825-For (5'-GGATCCGGATCCCACCGATCGCGAACATCGCG-3'; tandem BamHI sites underlined)/PA4825-Rev (5' -AAGCTTAAGCTTCTTGCCGACGCGCCGGGAAAG-3'; tandem HindIII sites underlined) in a reaction that included heating at $94{ }^{\circ} \mathrm{C}$ for $3 \mathrm{~min}$ followed by 30 cycles of $15 \mathrm{~s}$ at $94{ }^{\circ} \mathrm{C}, 30 \mathrm{~s}$ at $67.5^{\circ} \mathrm{C}$ and $3 \mathrm{~min}$ at $68^{\circ} \mathrm{C}$, before finishing with $10 \mathrm{~min}$ at $68{ }^{\circ} \mathrm{C}$. All reaction mixtures contained $50 \mathrm{ng} P$. aeruginosa IA614 chromosomal DNA, $30 \mathrm{pmol}$ of each primer, $0.2 \mathrm{mM}$ (each) dNTPs, and $1 \times$ KOD buffer (Invitrogen), which was heated to $94{ }^{\circ} \mathrm{C}$ before addition of 2 units of KOD DNA polymerase. Cloned genes were sequenced to ensure that no mutations had been introduced during PCR. The PA4358 ( feoB) gene was cloned into pRK415 following PCR amplification and initial cloning in pUC18. PA4358 was amplified using primer pair PA4358-For (5'-GACTAAGCTTAAGGACCTCGCCCTGCTGAC-3'; HindIII site underlined)/ PA4358-Rev (5'-GACTGAATTCTGGCGGCTGAGCTGTTTCAG-3'; 
Table 1. Bacterial strains and plasmids

\begin{tabular}{|c|c|c|}
\hline Strain or plasmid & Relevant properties* & Source or reference \\
\hline \multicolumn{3}{|l|}{ E. coli } \\
\hline $\operatorname{SM} 10\left(\lambda_{\text {pir }}\right)$ & thi-1 thr leu tonA lacY supE recA:: RP4-2-Tc:: Mu; $\mathrm{Km}^{\mathrm{r}} \lambda_{\text {pir }}$ & Miller \& Mekalanos (1988) \\
\hline S17-1 & thi pro hsdR recA $\mathrm{Tra}^{+}$ & Simon et al. (1983) \\
\hline \multicolumn{3}{|l|}{ P. aeruginosa } \\
\hline K2523 & IA614 PA3901 (fecA) :: mini-Tn5-tet $\$ \$$ & This study \\
\hline K2525 & IA614 PA4825 (mgtA) :: mini-Tn5-tet & This study \\
\hline K2931 & IA614 $\Delta$ PA4358 $($ feoB $)$ & This study \\
\hline K2932 & IA614 $\Delta p c o A \Delta \mathrm{PA} 4358($ feoB $)$ & This study \\
\hline K2556 & IA614 $\Delta$ PA4358 $(f e o B) \Delta$ PA4687 $\Delta$ PA5216 & This study \\
\hline K2530 & IA614 $\Delta p c o A \Delta$ PA4358 $($ feoB $) \Delta$ PA4687 $\Delta$ PA5216 & This study \\
\hline \multicolumn{3}{|l|}{ Plasmids } \\
\hline pBM001 & pK18MobSacB : : $\Delta p c o$ & This study \\
\hline pBM003 & pK18MobSacB : : $\triangle \mathrm{PA} 4687$ & This study \\
\hline pBM004 & pK18MobSacB : : $\triangle$ PA5216 & This study \\
\hline pEX18Tc & Gene-replacement vector; $s a c B \mathrm{Tc}^{\mathrm{r}}$ & Hoang et al. (1998) \\
\hline pCG003 & pEX18Tc: : $\Delta 4358(f e o B)$ & This study \\
\hline pUCP18 & P. aeruginosa-E. coli shuttle cloning vector; $\mathrm{Ap}^{\mathrm{r}} / \mathrm{Cb}^{\mathrm{r}}$ & Schweizer (1991) \\
\hline pBM11 & pUCP18::PA3901 (fecA) & This study \\
\hline pBM13 & pUCP18:: PA4825 (mgtA) & This study \\
\hline pRK415 & P. aeruginosa-E. coli shuttle cloning vector; $\mathrm{Tc}^{\mathrm{r}}$ & Keen et al. (1988) \\
\hline pCG002 & pRK415: : PA4358 (feoB) & This study \\
\hline
\end{tabular}

${ }^{\star} \mathrm{Ap}^{\mathrm{r}}$, ampicillin resistance; $\mathrm{Tc}^{\mathrm{r}}$, tetracycline resistance; $\mathrm{Km}^{\mathrm{r}}$, kanamycin resistance; $\mathrm{Cb}^{\mathrm{r}}$, carbenicillin resistance.

$\dagger$ Defective in pyoverdine, pyochelin and salicylate biosynthesis.

\$Gene disrupted by mini-Tn5-tet in the indicated insertion mutant derivatives of $P$. aeruginosa strain IA614 is identified using the designation given in the annotated genome sequence at http://www.pseudomonas.com.

§In instances where a PA gene has been annotated as a gene whose name and function have been established in another organism this gene name is given (in parentheses) along with the http://www.pseudomonas.com PA designation.

EcoRI site underlined) in a reaction mixture formulated as above except that Vent DNA polymerase and $1 \times$ ThermoPol buffer $(\mathrm{New}$ England Biolabs) were employed and DMSO was included at $2 \%$ $(\mathrm{v} / \mathrm{v})$. The reaction mixture was heated for $3 \mathrm{~min}$ at $94{ }^{\circ} \mathrm{C}$, followed by 30 cycles of $94{ }^{\circ} \mathrm{C}$ for $45 \mathrm{~s}, 63.9^{\circ} \mathrm{C}$ for $45 \mathrm{~s}, 72{ }^{\circ} \mathrm{C}$ for $2 \mathrm{~min}$, before finishing with $10 \mathrm{~min}$ at $72{ }^{\circ} \mathrm{C}$. The PA4358-containing PCR product was digested with HindIII and EcoRI, and cloned into pUC18 for sequencing before being subcloned into pRK415 to yield pCG002.

Mini-Tn5-tet mutagenesis. The pyoverdine- and pyochelin-deficient $P$. aeruginosa strain, IA614, was mutagenized with mini-Tn5-tet (de Lorenzo et al., 1990) following mobilization of mini-Tn5-tetcarrying plasmid pUT from E. coli SM10 $\left(\lambda_{\text {pir }}\right)$ as described previously (Sobel et al., 2005), with the IA614 mini-Tn5-tet insertion mutants selected on L-agar plates containing tetracycline $\left(60 \mu \mathrm{g} \mathrm{ml}^{-1}\right)$ and imipenem $\left(0.5 \mu \mathrm{g} \mathrm{ml}^{-1}\right.$; to counter-select donor E. coli). To screen for mutants with defects in citrate-mediated iron acquisition, two approaches were taken. Initially, the demonstration that the ethylenediaminedi( $o$-hydroxyphenylacetic) acid (EDDHA)-mediated (at $1.0 \mu \mathrm{g} \mathrm{ml}^{-1}$ ) growth inhibition of P. aeruginosa strain IA614 on Fe-deficient succinate minimal medium A could be relieved by $10 \mathrm{mM}$ citrate was used as an indicator of citrate-mediated iron acquisition, and mutants showing reduced or no citrate-stimulated growth were recovered as possibly defective in citrate-mediated iron acquisition. Subsequently, following the demonstration that a mutant disrupted in the gene encoding a homologue of the E. coli ferric citrate receptor (FecA) was unable to grow on Fe-deficient succinate minimal medium B supplemented with $0.1 \mathrm{M}$ citrate, potential ferric citrate uptake insertion mutants were identified by their failure to grow on citrate-containing Fe-deficient succinate minimal medium B agar plates. All mutants were tested for growth capability on $\mathrm{Fe}-$ deficient succinate minimal agar lacking citrate to ensure that they lacked only the ability to respond to/grow in the presence of citrate and were not, for example, generally defective in iron acquisition or, possibly, auxotrophic. Chromosomal DNA flanking the mini-Tn5-tet element in putative ferric citrate utilization mutants was cloned on PstI fragments and sequenced as before (Cao et al., 2004). The disrupted genes were then identified by BLASTN (http:// www.ncbi.nlm.nih.gov/BLAST/) searches of the available $P$. aeruginosa genome sequence (http://www.pseudomonas.com) (Stover et al., 2000).

Growth assay. Overnight cultures of $P$. aeruginosa grown in ironlimited succinate minimal medium B were subcultured in the same medium substituted with EDDHA $\left(1 \mu \mathrm{g} \mathrm{ml}^{-1}\right)$ with or without citrate $(25 \mathrm{mM})$, pyoverdine $\left(100 \mu \mathrm{g} \mathrm{ml}^{-1}\right.$; prepared as described in 
Meyer et al., 1998) or desferrioxamine B (Sigma; $80 \mu \mathrm{M}$ ) to a final $\mathrm{OD}_{600}$ of $\sim 0.1$. Cultures were incubated at $37{ }^{\circ} \mathrm{C}$ and $\mathrm{OD}_{600}$ readings were taken every hour for 5-8 h. In experiments involving the $P$. aeruginosa quadruple deletion mutant K2530, bacteria were grown overnight in pyoverdine-supplemented $\left(100 \mu \mathrm{g} \mathrm{ml} \mathrm{m}^{-1}\right)$ minimal medium B, harvested and washed with an equal volume of minimal medium B (to remove traces of pyoverdine) prior to subculture. In some instances, overnight cultures were diluted 1:199 in the above media and growth assessed visually after $18 \mathrm{~h}$ incubation. Owing to EDDHA no longer being available commercially, later experiments were carried out using the related metal chelator, ethylenediaminediacetic acid (EDDA) at $8 \mu \mathrm{g} \mathrm{ml}^{-1}$ in place of EDDHA.

Transport assay. P. aeruginosa cells were cultured to late exponential phase $\left(\mathrm{OD}_{600} 1.6\right)$ in iron-limited succinate minimal medium $\mathrm{B}$ with or without $1 \mathrm{mM}$ citrate, washed once in medium $\mathrm{B}$ without citrate and resuspended in the same medium at $\mathrm{OD}_{600} 0.1 .{ }^{55} \mathrm{Fe}$-citrate was prepared by incubating $24 \mathrm{pmol}{ }^{55} \mathrm{FeCl}_{3}$ (PerkinElmer) and $50 \mu \mathrm{mol}$ citrate in $50 \mu \mathrm{l}$ at room temperature for $30 \mathrm{~min}$ before diluting 10fold with iron-limited succinate minimal medium $B$. The uptake assay was initiated by adding $5 \mu$ of the diluted ${ }^{55} \mathrm{Fe}$-citrate mixture to $1 \mathrm{ml}$ cells (preincubated for $5 \mathrm{~min}$ at $37^{\circ} \mathrm{C}$ ) and was allowed to proceed for $15 \mathrm{~min}$ at $37^{\circ} \mathrm{C}$. Cells were then harvested by centrifugation (12000 r.p.m., $2 \mathrm{~min}$ ), washed three times with iron-limited succinate minimal medium $B(1 \mathrm{ml})$ and resuspended vigorously in liquid scintillation cocktail ( $10 \mathrm{ml}$; Ultima Gold, PerkinElmer). Cellassociated radioactivity was measured using a model 1214 Rackbeta counter (LKB-Wallac). In some experiments, the uncoupler KCN $(10 \mathrm{mM})$ was added to bacterial cells $5 \mathrm{~min}$ prior to addition of the ${ }^{55} \mathrm{Fe}$-citrate mixture.

Site-directed deletion mutagenesis. To introduce deletions of one or more of the four annotated $\mathrm{Fe}^{2+} / \mathrm{Fe}^{3+}$ transport genes [pco (PA2065), PA4358, PA4687 and PA5216] into P. aeruginosa, deletion constructs were first prepared in plasmid pK18MobSacB (except for PA4358, which was engineered into pEX18Tc) by cloning PCRamplified $1 \mathrm{~kb}$ DNA fragments corresponding to the regions upstream and downstream, respectively, of the sequences to be deleted. All PCR mixtures contained $50 \mathrm{ng} P$. aeruginosa IA614 chromosomal DNA, 30 pmol of forward and reverse primer, $0.2 \mathrm{mM}$ (each) dNTPs, and $1 \times$ ThermoPol buffer (New England Biolabs) in $50 \mu \mathrm{l}$ final volume. The upstream and downstream segments were amplified separately, cloned into pCR-Blunt II-TOPO using the Zero Blunt TOPO PCR cloning kit (Invitrogen), sequenced to verify that no mutations had been introduced during PCR, excised with appropriate restriction digestions and cloned sequentially into $\mathrm{pK} 18 \mathrm{MobSacB}$ (or pEX18Tc) to yield the desired deletion construct ( $\Delta$ pco, pBM001; $\triangle$ PA4358, pCG003; $\triangle \mathrm{PA} 4687, \mathrm{pBM} 003 ; \Delta \mathrm{PA} 5216$, $\mathrm{pBM} 004)$. Deletion-containing $\mathrm{pK} 18 \mathrm{MobSacB}$ or pEX18Tc derivatives were then mobilized into P. aeruginosa strain IA614 as described previously (Sobel et al., 2003), and transconjugants carrying the plasmid in the chromosome were selected on L-agar plates containing kanamycin $\left(1500 \mu \mathrm{g} \mathrm{ml}^{-1}\right.$; pKMobSacB) or tetracycline $\left(75 \mu \mathrm{g} \mathrm{ml}^{-1}\right.$; $\mathrm{pEX} 18 \mathrm{Tc})$ and imipenem $\left(0.5 \mu \mathrm{g} \mathrm{ml}{ }^{-1}\right.$; to counter-select E. coli). Kanamycin- or tetracycline-resistant colonies were streaked onto Lagar plates containing $10 \%(\mathrm{w} / \mathrm{v})$ sucrose, and sucrose-resistant colonies were screened for the presence of the respective deletions using colony PCR (Redly \& Poole, 2003). Primers and cycling parameters are provided in the supplementary material available with the online version of this paper.

Outer-membrane proteins. Fractions containing outer-membrane proteins were prepared from $18 \mathrm{~h}$ cultures $(50 \mathrm{ml})$ of $P$. aeruginosa grown in iron-deficient or iron-supplemented $\left(100 \mu \mathrm{M} \mathrm{FeCl}_{3}\right)$ medium B with or without citrate (1 or $25 \mathrm{mM}$ ) using a previously described protocol (Srikumar et al., 1998). Briefly, cells were harvested by centrifugation, stored on ice for $30 \mathrm{~min}$ and then processed as before to isolate cell envelopes. These were then extracted with $2 \%(\mathrm{v} / \mathrm{v})$ Triton X-100-20 mM Tris/HCl ( $\mathrm{pH} \mathrm{8.0)}$ and the outer-membrane proteins were recovered in the pellet fraction following centrifugation.

SDS-PAGE and immunoblotting. Outer-membrane preparations were electrophoretically separated on SDS-polyacrylamide $[10 \%$ $(\mathrm{w} / \mathrm{v})$ ] gels and electrotransferred onto Immobilon-P PVDF membrane (Millipore) as described previously (Srikumar et al., 1998). Equal loading of protein in all wells was confirmed by rapid Coomassie staining of duplicate gels (Faguy et al., 1996). Membranes were probed with 1:1999 dilution of polyclonal anti-E. coli FecA antiserum (provided by Dr V. Braun, Max Planck Institute for Developmental Biology, Tübingen, Germany).

Reverse-transcriptase (RT)-PCR. An overnight culture of $P$. aeruginosa IA614 grown in iron-deficient medium A was diluted $1: 9$ in the same medium with or without $\mathrm{FeCl}_{3}(100 \mu \mathrm{M})$ or citrate $(1 \mathrm{mM})$ and grown for $2 \mathrm{~h}$ with shaking at $37{ }^{\circ} \mathrm{C}$. Total cellular RNA was isolated using the Qiagen RNeasy Mini kit and RNase-free DNase (Qiagen) and a protocol provided by the manufacturer. The reverse transcription (RT)-PCR was performed with $\sim 500$ ng RNA using the Qiagen One Step RT-PCR kit, again according to a protocol provided by the manufacturer. Primer pairs rpsL-F (5'-GCAACTATCAACCAGCTG-3')/rpsL-R (5'-GCTGTGCTCTTGCAGGTTGTG$\left.3^{\prime}\right)$ and fecA-F (5'-CACGACCTGGCATTGAACTTCG-3')/fecA-R (5'-CACGTTGTGG-GTGGTCTTCAGG-3') were used to assess expression of the $r p s L$ and PA3901 ( $f e c A$ ) genes, respectively. Reaction mixtures were incubated for $30 \mathrm{~min}$ at $50{ }^{\circ} \mathrm{C}$ and $15 \mathrm{~min}$ at $95{ }^{\circ} \mathrm{C}$, followed by $25-35$ cycles of $30 \mathrm{~s}$ at $94{ }^{\circ} \mathrm{C}, 30 \mathrm{~s}$ at $58{ }^{\circ} \mathrm{C}$, and $1 \mathrm{~min}$ at $72{ }^{\circ} \mathrm{C}$, before finishing with $10 \mathrm{~min}$ at $72{ }^{\circ} \mathrm{C}$.

\section{RESULTS}

\section{Screening a $P$. aeruginosa mini-Tn5-tet insertion library for mutants deficient in citrate-mediated Fe acquisition}

$P$. aeruginosa strain IA614 is deficient in endogenous siderophore production and unable to grow in Fe-limited minimal medium A supplemented with the Fe chelator EDDHA unless supplied with an exogenous 'siderophore' such as citrate (e.g. see Fig. 1A). Thus, citrate-promoted growth of strain IA614 in EDDHA-containing Fe-deficient minimal medium can be used as an indirect measure of citrate-promoted Fe acquisition. To identify genes involved in citrate-promoted Fe acquisition, a $P$. aeruginosa IA614 mini-Tn5-tet insertion mutant library was screened for lack of or reduced growth on Fe-deficient solid media supplemented with EDDHA and citrate. Of approximately 2700 mutants screened, two showed consistently reduced growth on the EDDHA/citrate plates but not on unsupplemented medium A plates. The mini-Tn5-tet element was inserted in the PA3901 gene encoding a homologue (63\% identical) of the FecA outer-membrane ferric citrate receptor of $E$. coli in both mutants. One of these mutants, $\mathrm{K} 2523$, was subsequently confirmed as defective for growth in EDDHA- and citrate-supplemented Fe-deficient minimal medium, though it grew as well as its parent strain in unsupplemented Fe-limited medium (Fig. 1A). The mutant also grew well in EDDHA-supplemented Fe-limited 

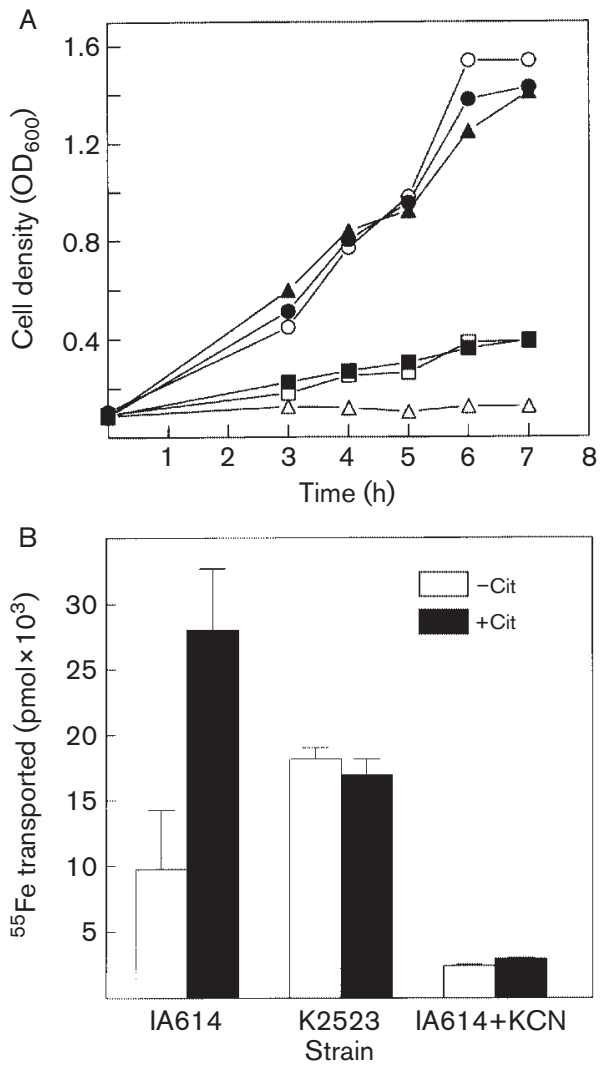

Fig. 1. FecA-dependent citrate-mediated $\mathrm{Fe}$ acquisition in $P$. aeruginosa. (A) Citrate-promoted growth of $P$. aeruginosa in $\mathrm{Fe}-$ restricted minimal medium. $P$. aeruginosa IA614 $\left(\mathrm{FecA}^{+}\right.$; solid symbols) and $\mathrm{K} 2523$ ( $\mathrm{FecA}^{-}$; open symbols) were subcultured in Fe-deficient succinate minimal medium without supplementation $(\bullet, \bigcirc)$ or supplemented with $\operatorname{EDDHA}\left(1 \mu \mathrm{g} \mathrm{m}^{-1}\right)(\boldsymbol{\square}, \square)$ or EDDHA $\left(1 \mu \mathrm{g} \mathrm{ml}^{-1}\right)$ and citrate $(25 \mathrm{mM})(\boldsymbol{\Lambda}, \triangle)$ and growth was measured as a function of time. The data are representive of a minimum of three independent experiments. (B) Citrate-mediated Fe uptake in $P$. aeruginosa IA614 $\left(\mathrm{FecA}^{+}\right)$and $\mathrm{K} 2523\left(\mathrm{FecA}^{-}\right)$ grown in Fe-deficient succinate minimal medium with $(+\mathrm{Cit})$ or without $(-\mathrm{Cit})$ citrate $(1 \mathrm{mM})$. Data are reported as pmol ${ }^{55} \mathrm{Fe}$ accumulated after $15 \mathrm{~min}$ incubation of $1 \mathrm{ml} P$. aeruginosa cells in medium containing citrate $(50 \mu \mathrm{mol})$ and ${ }^{55} \mathrm{FeCl}_{3}(24 \mathrm{pmol})$ with or without prior treatment with $\mathrm{KCN}(10 \mathrm{mM})$ as indicated. The mean \pm SD of three independent experiments is shown.

medium containing pyoverdine $\left(100 \mu \mathrm{g} \mathrm{ml}^{-1}\right)$ or $\mathrm{FeCl}_{3}$ $(100 \mu \mathrm{M}) \quad$ (data not shown) indicating that it was specifically deficient in citrate-promoted growth. In transport assays, the parent strain, IA614, showed enhanced citrate-promoted $\mathrm{Fe}$ acquisition when cultured in Fe-limited medium supplemented with citrate as compared to citrate-free medium (Fig. 1B), in parallel with the increased $f e c A$ expression (Fig. 2A) and FecA production (Fig. 2B) in citrate-supplemented Fe-limited medium. Citrate-promoted $\mathrm{Fe}$ acquisition was drastically reduced in $\mathrm{KCN}$-treated strain IA614 grown with or without citrate and virtually no enhanced $\mathrm{Fe}$ acquisition

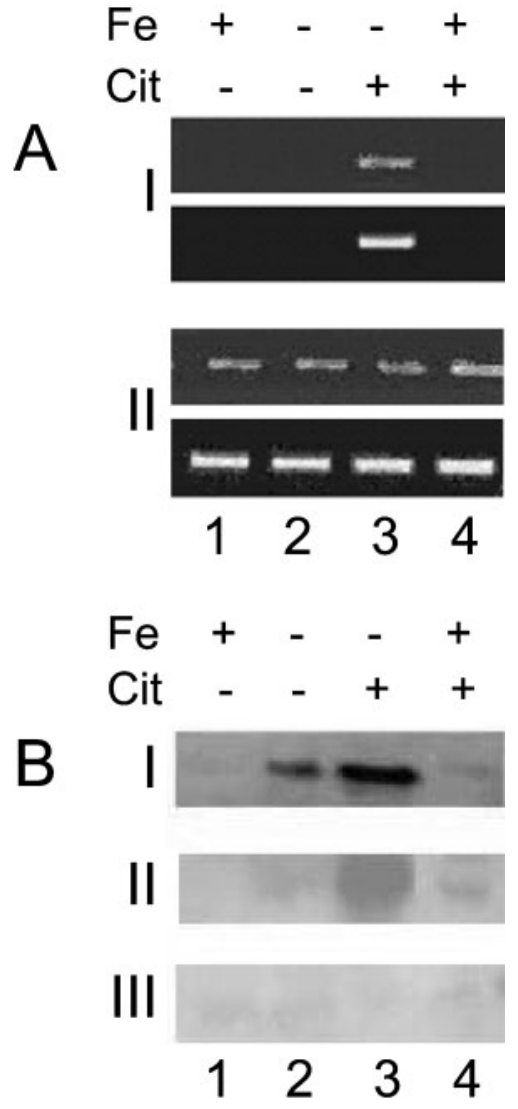

Fig. 2. Citrate-inducible expression of $f e c A$ and FecA in $P$. aeruginosa. $P$. aeruginosa IA614 (Al/All and $\mathrm{Bl} / \mathrm{BII})$ ) and its $\mathrm{FecA}^{-}$ derivative $\mathrm{K} 2523$ (BIII) were cultivated in Fe-deficient $(-\mathrm{Fe})$ and Fe-sufficient $(+\mathrm{Fe})$ succinate minimal medium with $(+\mathrm{Cit})$ or without (-Cit) citrate $(1 \mathrm{mM}$, panels $\mathrm{A}$ and panel $\mathrm{Bl}$; $25 \mathrm{mM}$, panels $\mathrm{BII}$ and $\mathrm{BIII}$ ). (A) Expression of fecA (Al) and rpsL (All) was assessed using semiquantitative RT-PCR. The rps $L$ reaction served as an internal control that ensured equal amounts of RNA were employed in all of the RT-PCRs shown. The PCR portion of the reactions was carried out for 27 (top panel in $\mathrm{Al}$ and $\mathrm{All}$ ) or 28 (bottom panel in Al and All) cycles. (B) Production of FecA was assessed using Western immunoblotting of outer-membrane protein fractions developed with antibody to $E$. coli FecA. The lack of cross-reactivity of this antibody with outer-membrane protein fractions of the $\mathrm{FecA}^{-}$stain $\mathrm{K} 2523$ (panel III) confirms its specificity for FecA in $P$. aeruginosa.

was seen in citrate-grown (vs citrate-free) cells (Fig. 1B), consistent with the observed citrate-promoted Fe acquisition being an active process. In contrast to strain IA614, the fecA (PA3901) mutant showed no increase in citratemediated $\mathrm{Fe}$ acquisition when grown in citrate-supplemented Fe-limited medium (Fig. 1B), consistent with the strain being deficient in citrate-inducible ferric citrate uptake and with the lack of FecA (Fig. 2B). Finally, the cloned fecA (PA3901) gene restored growth of strain K2523 in EDDHA- and citrate-supplemented Fe-deficient minimal medium (Fig. 3A) and citrate-promoted $\mathrm{Fe}$ 

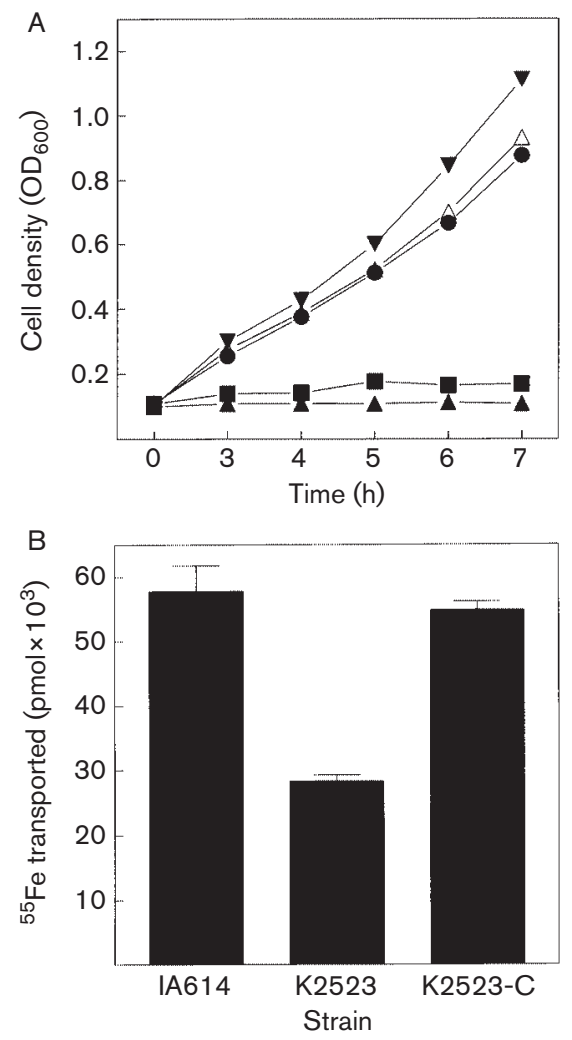

Fig. 3. Complementation of the citrate-promoted growth and $\mathrm{Fe}$ transport defects of $\mathrm{FecA}^{-} P$. aeruginosa with cloned fecA. (A) $P$. aeruginosa $\mathrm{K} 2523\left(\mathrm{FecA}^{-}\right)(\boldsymbol{\Delta}), \mathrm{K} 2523$ carrying the fecA plasmid pBM11 $(\triangle)$ and $P$. aeruginosa IA614 $\left(\mathrm{FecA}^{+}\right)(\boldsymbol{\nabla})$ were subcultured in succinate minimal medium supplemented with EDDHA $\left(1 \mu \mathrm{g} \mathrm{ml}^{-1}\right)$ and citrate $(25 \mathrm{mM})$ and growth was measured as a function of time. Growth of strain K2523 in Fedeficient succinate minimal medium without supplementation $(\bullet)$ or supplemented with EDDHA $\left(1 \mu \mathrm{g} \mathrm{m} l^{-1}\right)$ alone $(\boldsymbol{\square})$ is also shown. The data are representive of a minimum of three independent experiments. (B) Citrate-mediated Fe uptake in $P$. aeruginosa $\mathrm{K} 2523\left(\mathrm{FecA}^{-}\right)$, its pBM11-harbouring derivative (K2523-C), and IA614 $\left(\mathrm{FecA}^{+}\right)$grown in Fe-deficient succinate minimal medium with citrate $(1 \mathrm{mM})$. Data are reported as pmol ${ }^{55} \mathrm{Fe}$ accumulated after $15 \mathrm{~min}$ incubation of $1 \mathrm{ml} P$. aeruginosa cells in medium containing citrate $(50 \mu \mathrm{mol})$ and ${ }^{55} \mathrm{FeCl}_{3}$ (24 pmol). The mean \pm SD of three independent experiments is shown.

acquisition in citrate-grown cells (Fig. 3B). PA3901 is, thus, confirmed as the ferric citrate receptor in $P$. aeruginosa and is hereafter described as FecA.

\section{Evidence for citrate delivery of $\mathrm{Fe}^{2+}$ to $P$. aeruginosa}

While the recovery of the $f e c A$ gene validated the previous screen, it was not unexpected and provided no insights as regards post-outer-membrane constituents for ferric citrate uptake in $P$. aeruginosa. Still, with an available mutant defective in citrate-mediated $\mathrm{Fe}$ acquisition it was possible to develop a second screen more robust than the first, which relied on the observed inability of a mutant deficient in citrate-mediated $\mathrm{Fe}$ acquisition to grow in the presence of excess citrate. Using a second Fe-limited minimal medium (medium B) it was observed, for example, that the addition of $0.1 \mathrm{M}$ citrate completely inhibited growth of $\mathrm{FecA}^{-}$strain K2353 but not its $\mathrm{FecA}^{+}$parent, strain IA614 (data not shown), presumably because all available $\mathrm{Fe}$ is complexed to citrate at such high concentrations, making it unavailable to a mutant deficient in ferric citrate uptake. To obtain mutants compromised for citrate-mediated $\mathrm{Fe}$ acquisition, then, 6000 mini-Tn5-tet insertion mutants of strain IA614 were subsequently screened for lack of growth on $0.1 \mathrm{M}$ citrate-supplemented Fe-limited minimal medium B. Of several non-growing mutants recovered, two grew on unsupplemented medium B (i.e. were not auxotrophs). One mutant was again disrupted in the fecA gene while the second, strain K2525, had the mini-Tn5-tet element inserted into the PA4825 gene encoding a homologue of the MgtA and $\mathrm{MgtB} \mathrm{Mg}{ }^{2+}$ transporters of Salmonella enterica serovar Typhimurium ( $52 \%$ and $69 \%$ identical, respectively). The growth deficiency of strain K2525 in EDDHA- and citratesupplemented medium B was reversed by the cloned $m g t A$ (PA4825) gene (Fig. 4), indicating that it resulted from disruption of $m g t A$ (PA4825). A link to citrate-mediated Fe acquisition was not obvious, however, suggesting that the growth deficiency of the mgtA (PA4825) mutant might be explainable by a sensitivity to citrate. In agreement with this, pyoverdine- $\left(100 \mu \mathrm{g} \mathrm{ml}^{-1}\right)$ or $\mathrm{FeCl}_{3^{-}}(100 \mu \mathrm{M})$ mediated growth promotion of strain K2525 in EDDHA-containing Fe-limited medium B was abrogated in the presence but not the absence of citrate $(0.1 \mathrm{M})$ (assessed visually after $18 \mathrm{~h}$; data not shown). This contrasted with the $\mathrm{FecA}^{-}$K2523 mutant, where pyoverdine- and $\mathrm{FeCl}_{3}$-mediated growth promotion in EDDHA-containing medium was not abrogated by citrate (data not shown). Intriguingly, mutants of $S$. enterica defective in both $m g t A$ and $m g t B$ show enhanced Fe accumulation and increased $\mathrm{Fe}^{2+}$-dependent oxidative killing, the loss of these transporters apparently affecting the expression or activity of other metal transporters capable of accommodating Fe (Chamnongpol \& Groisman, 2002). These results were consistent with loss of the $\mathrm{Mg}^{2+}$ transporters ultimately promoting $\mathrm{Fe}^{2+}$ acquisition and suggest, in light of the citrate sensitivity of an $m g t A$ mutant in $P$. aeruginosa, that Fe delivered to $P$. aeruginosa by citrate may ultimately be entering the cell as $\mathrm{Fe}^{2+}$.

\section{Contribution of the $\mathrm{FeoB} \mathrm{Fe}^{2+}$ transporter to citrate-promoted $\mathrm{Fe}$ acquisition}

Should citrate ultimately provide Fe to cells as $\mathrm{Fe}^{2+}$, then a mutant deficient in $\mathrm{Fe}^{2+}$ transport across the cytoplasmic membrane should be defective in citrate-promoted $\mathrm{Fe}$ acquisition. A cytoplasmic membrane $\mathrm{Fe}^{2+}$ transporter, FeoB, has been described in E. coli (Hantke, 1987; Kammler et al., 1993) and other Gram-negative bacteria (Katoh et al., 2001; Naikare et al., 2006; Robey \& Cianciotto, 2002; 


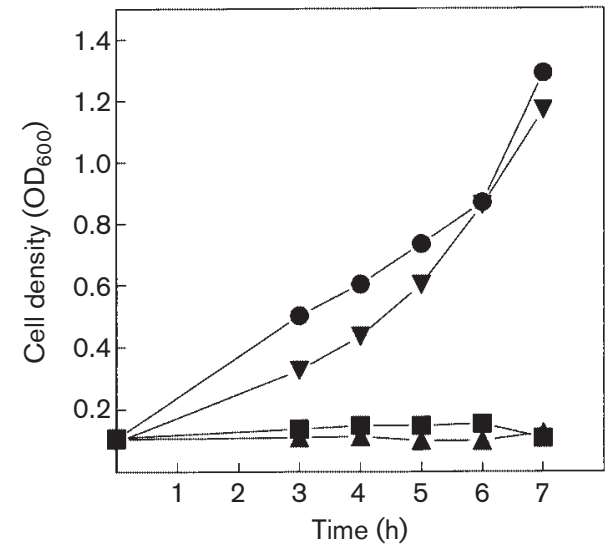

Fig. 4. Defect in citrate-promoted growth of a $P$. aeruginosa PA4825 ( $m g t A)$ mutant in Fe-restricted medium. $P$. aeruginosa $\mathrm{K} 2525\left(\mathrm{MgtA}^{-}\right)$was subcultured in Fe-deficient succinate minimal medium without supplementation ( $)$ or supplemented with EDDHA $\left(1 \mu \mathrm{g} \mathrm{ml}^{-1}\right)(\boldsymbol{\square})$ or EDDHA $\left(1 \mu \mathrm{g} \mathrm{ml}^{-1}\right)$ and citrate $(25 \mathrm{mM})(\boldsymbol{\Delta})$ and growth was measured as a function of time. Growth of K2525 carrying the mgtA plasmid pBM13 in this medium is also shown $(\boldsymbol{\nabla})$. The data are representive of a minimum of three independent experiments.
Velayudhan et al., 2000; Wyckoff et al., 2006) and a homologue has been identified in $P$. aeruginosa (PA4358; $67.5 \%$ identical to E. coli FeoB). To assess a role for $f e o B$ (PA4358) in citrate-mediated Fe acquisition, the gene was deleted in strain IA614 and the impact on citrate-promoted growth in Fe-limited medium supplemented with the $\mathrm{Fe}$ chelator EDDA (Fig. 5A, top panel) and citrate-promoted Fe uptake (Fig. 5B) was assessed. Loss of $f e o B$ (PA4358) markedly reduced growth in EDDA and citrate-supplemented medium as well as citrate-promoted Fe uptake (Fig. 5, compare IA614 and K2931), consistent with the involvement of this $\mathrm{Fe}^{2+}$ transporter in citrate-mediated $\mathrm{Fe}$ acquisition. The cloned $f e o B$ (PA4358) gene restored citrate-promoted growth of strain K2931 in EDDAsupplemented minimal medium [Fig. 6A, compare growth of K2931 carrying pCG002 (pRK415:: PA4358) vs K2931 carrying pRK415], though plasmid-bearing K2931 strains grew much slower than their plasmid-free counterparts (Fig. 6A). Cloned $f e o B$ also restored citrate-mediated $\mathrm{Fe}$ acquisition in strain K2931 (Fig. 6B). As in EDDHAcontaining Fe-limited medium (Fig. 1A), citrate failed to promote growth of the fecA mutant K2523 in EDDAcontaining medium (data not shown), confirming the need for FecA for citrate-promoted Fe acquisition.
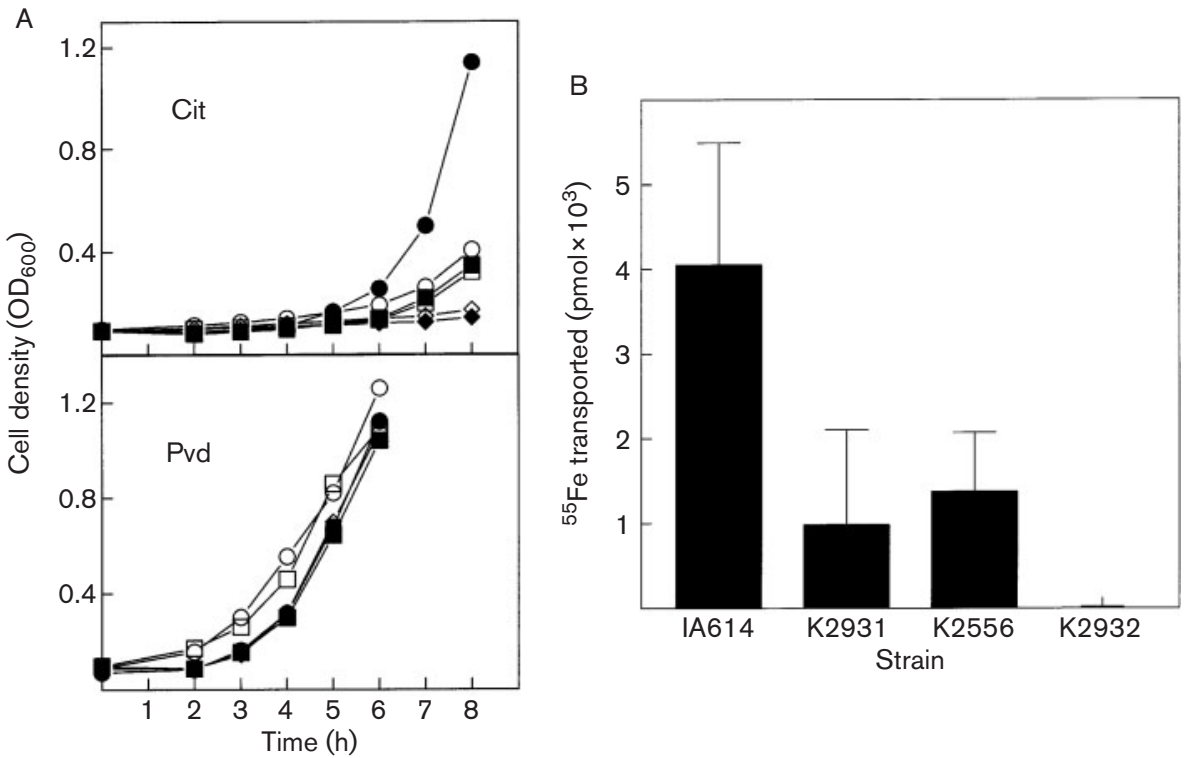

Fig. 5. FeoB-dependent citrate-mediated Fe acquisition in $P$. aeruginosa. (A) Defect in citrate-promoted growth of $P$. aeruginosa PA4358 $(f e o B)$ mutants in Fe-restricted medium. P. aeruginosa IA614 (parent strain; $\mathbf{0}), \mathrm{K} 2931(\Delta f e o B ; \mathbf{\square})$, $\mathrm{K} 2932(\Delta$ feoB $\Delta p c o A ; \bigcirc), \mathrm{K} 2556(\Delta f e o B \Delta \mathrm{PA} 4687 \Delta \mathrm{PA} 5216 ; \square)$ and K2530 ( $\Delta$ feoB $\Delta p c o A \Delta \mathrm{PA} 4687 \Delta \mathrm{PA} 5216 ; \diamond)$ were subcultured in succinate minimal medium supplemented with EDDA ( $8 \mu \mathrm{g} \mathrm{ml}^{-1}$ ) and either citrate (25 mM) (Cit; top panel) or pyoverdine $\left(100 \mu \mathrm{g} \mathrm{ml}^{-1}\right)(\mathrm{Pvd}$; bottom panel) and growth was monitored as a function of time. Growth of IA614 in succinate minimal medium supplemented with EDDA $\left(8 \mu \mathrm{g} \mathrm{ml}^{-1}\right)$ only $(\boldsymbol{)})$ is shown (top panel) as a representative control highlighting lack of growth in the absence of siderophore. (B) Citrate-mediated Fe uptake in $P$. aeruginosa IA614 and its FeoB ${ }^{-}$derivatives K2931 $(\Delta f e o B), \mathrm{K} 2556(\Delta f e o B \Delta \mathrm{PA} 4687 \Delta \mathrm{PA} 5216)$ and $\mathrm{K} 2932(\Delta f e o B \Delta p c o A)$ grown in Fe-deficient succinate minimal medium with citrate $(1 \mathrm{mM})$. Data are reported as pmol ${ }^{55} \mathrm{Fe}$ accumulated after 15 min incubation of $1 \mathrm{ml} P$. aeruginosa cells in medium containing citrate $(50 \mu \mathrm{mol})$ and ${ }^{55} \mathrm{FeCl}_{3}(24 \mathrm{pmol})$ and have been adjusted to eliminate uptake seen in cells grown without citrate. The mean $\pm \mathrm{SD}$ of three independent experiments is shown. 

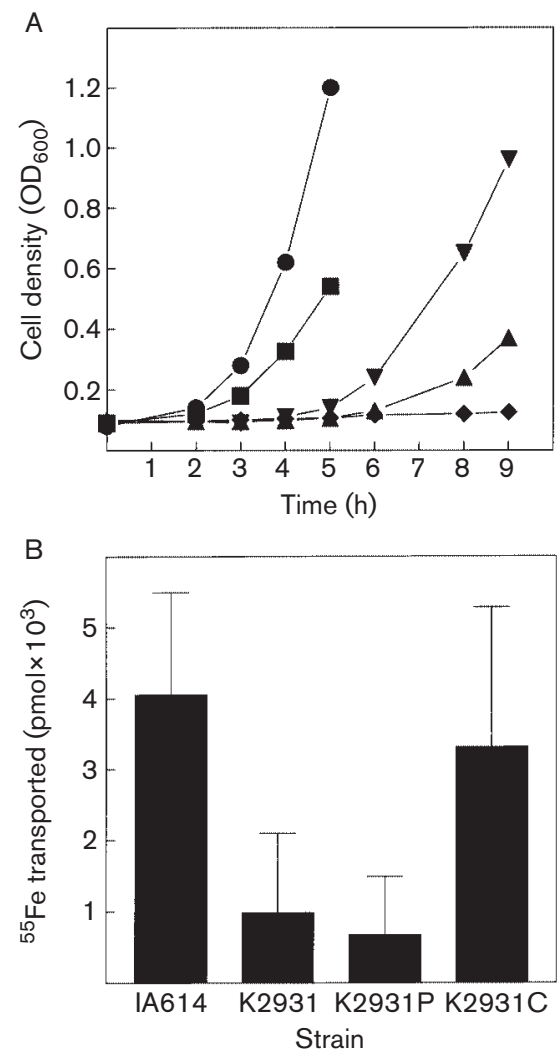

Fig. 6. Complementation of the citrate-promoted growth and $\mathrm{Fe}$ transport defects of $\mathrm{FeoB}^{-} P$. aeruginosa with cloned feoB. (A) $P$. aeruginosa $\mathrm{K}_{2931}\left(\mathrm{FeoB}^{-} ; \mathbf{\square}\right), \mathrm{K}_{2931}$ carrying plasmid pCG002 (pRK415::feoB; $\boldsymbol{\nabla}$ ) or pRK415 without insert $(\boldsymbol{A})$, and $P$. aeruginosa IA614 (FeoB ${ }^{+}$; 0 ) were subcultured in succinate minimal medium supplemented with EDDA $\left(8 \mu \mathrm{g} \mathrm{ml}^{-1}\right)$ and citrate $(25 \mathrm{mM})$ and growth was measured as a function of time. Growth of IA614 in succinate minimal medium supplemented with EDDA $\left(8 \mu \mathrm{g} \mathrm{ml}^{-1}\right)$ only $(\boldsymbol{)})$ is shown as a representative control highlighting lack of growth in the absence of citrate. The data are representative of a minimum of three independent experiments. (B) Citrate-mediated Fe uptake in $P$. aeruginosa $\mathrm{K}^{2931}\left(\mathrm{FeoB}^{-}\right)$, its pCG002- (K2931C) and pRK415- (K2391P) harbouring derivatives, and $P$. aeruginosa $\mathrm{IA} 614\left(\mathrm{FeoB}^{+}\right)$grown in $\mathrm{Fe}-$ deficient succinate minimal medium with citrate $(1 \mathrm{mM})$. Data are reported as pmol ${ }^{55} \mathrm{Fe}$ accumulated after 15 min incubation of $1 \mathrm{ml} P$. aeruginosa cells in medium containing citrate $(50 \mu \mathrm{mol})$ and ${ }^{55} \mathrm{FeCl}_{3}(24 \mathrm{pmol})$. The mean $\pm \mathrm{SD}$ of three independent experiments is shown.

\section{Contribution of the PcoA ferroxidase to citrate- promoted $\mathrm{Fe}$ acquisition}

Residual growth and Fe transport are clearly evident in the $\Delta f e o B$ (PA4358) mutant K2931, suggesting that additional $\mathrm{Fe}$ transporters can function in citrate-promoted $\mathrm{Fe}$ acquisition. Two operons encoding homologues of $\mathrm{Fe}^{3+}$ transporters in other bacteria have been annotated in $P$. aeruginosa, PA5216-5217 (homologue of the HitABC system in Haemophilus influenzae) (Sanders et al., 1994) and PA4687-4688 (homologue of the SfuABC and FbpABC systems in Serratia marcescens and Neisseria spp., respectively) (Adhikari et al., 1996; Angerer et al., 1992). Disruption of PA5216 (45\% identical to HitA) and PA4687 (30\% identical to SfuB) in K2931, yielding the triple knockout strain K2556, did not further compromise citrate-promoted growth in EDDA-containing medium (Fig. 5A, top panel) or citrate-mediated Fe uptake (Fig. 5B). These putative $\mathrm{Fe}^{3+}$ transport systems are, therefore, not involved in citrate-promoted $\mathrm{Fe}$ acquisition. Recently, a periplasmic multicopper oxidase with demonstrated ferroxidase activity, PcoA, has been shown to play a role in $\mathrm{Fe}^{2+}$ transport in P. aeruginosa, apparently functioning to oxidize $\mathrm{Fe}^{2+}$ to $\mathrm{Fe}^{3+}$ for subsequent transport via $\mathrm{Fe}^{3+}$ transporters (Huston et al., 2002). A mutant strain, K2932, lacking both $f e o B$ (PA4358) and $p c o A$ was also not more compromised for growth in EDDA-containing minimal medium (Fig. 5A, top panel) though intriguingly it was completely deficient in citrate-mediated $\mathrm{Fe}$ uptake (Fig. 5B). Elimination of $p c o A$ from K2556 to produce a $\triangle p c o A \quad \Delta f e o B$ (PA4358) $\Delta$ PA4687 $\Delta$ PA5216 quadruple deletion mutant did, however, completely abrogate citrate-promoted growth in EDDA-containing medium (Fig. 5A, top panel). None of the mutants showed any defect in pyoverdine- (Fig. 5A, bottom panel) or ferrioxamine B- (data not shown) promoted growth in EDDA-supplemented minimal medium, indicating that these $\mathrm{Fe}^{2+} / \mathrm{Fe}^{3+}$ transport components were not important for Fe transport mediated by these other siderophores.

\section{DISCUSSION}

Citrate promotion of $\mathrm{Fe}$ acquisition in P. aeruginosa has been known for some time, though when first reported it was seen to be independent of citrate in the growth medium and was, paradoxically, lowest in cells grown with citrate (Cox, 1980b). Still, a study by Harding \& Royt (1990) clearly showed that a citrate-inducible ferric citrate uptake mechanism is present in $P$. aeruginosa grown under Fe-limiting conditions. Moreover, these authors confirmed that a citrate-inducible ferric citrate-binding activity was present in the outer membrane of this organism (Harding \& Royt, 1990) reminiscent of the FecA ferric citrate receptor of E. coli (Braun, 2003). While a fecA homologue has been identified in $P$. aeruginosa (PA3901) (Ochsner et al., 2002) and ferric citrate-promoted biofilm formation by $P$. aeruginosa requires this $f e c A$ gene (Banin et al., 2005), consistent with PA3901 functioning as a ferric citrate receptor, the results presented here represent the first confirmation that PA3901 does indeed function as a receptor for ferric citrate. As in E. coli (Braun, 2003), and in agreement with the results of Harding \& Royt (1990), $P$. aeruginosa $\mathrm{FecA}$ is found in the outer membrane of $\mathrm{Fe}$ limited cells grown in the presence of citrate. In E. coli, the citrate-inducibility of $f e c A$ and the other ferric citrate transport components under $\mathrm{Fe}$-limiting conditions is dependent upon the $f e c I R$ genes, encoding an ECF sigma 
factor and its cognate anti-sigma factor (Braun \& Mahren, 2005; Braun et al., 2006; Visca et al., 2002). fecIR homologues have been described in $P$. aeruginosa (PA3899, PA3900), where they are linked to $f e c A$ on the chromosome and have been shown to be strongly induced under Fe-limiting conditions (Ochsner et al., 2002), consistent with a role in mediating the citrate inducibility of $f e c A$ under conditions of $\mathrm{Fe}$ limitation. While some induction of $P$. aeruginosa FecA in citrate-free Fe-limited medium was apparent in immunoblots, in agreement with earlier results showing modest Fe-limitation-inducibility of PA3901 (Ochsner et al., 2002), maximal expression was citrate-dependent.

In the absence of obvious genes for a cytoplasmic membrane ferric citrate permease, the observation that a $f e o B$ mutant is compromised for citrate-promoted $\mathrm{Fe}$ acquisition provides important insights into the mechanism of citrate-mediated Fe uptake in $P$. aeruginosa. It is now well established that FeoB, first described as a cytoplasmic membrane $\mathrm{Fe}^{2+}$ transporter in E. coli (Hantke, 1987; Kammler et al., 1993), contributes to $\mathrm{Fe}^{2+}$ uptake in a variety of micro-organisms including Helicobacter pylori (Velayudhan et al., 2000), Vibrio cholerae (Wyckoff et al., 2006), Campylobacter jejuni (Naikare et al., 2006), Legionella pneumophila (Robey \& Cianciotto, 2002) and Synechocystis sp. strain PCC 6803 (Katoh et al., 2001). As such, FeoB's demonstrated involvement in citrate-mediated $\mathrm{Fe}$ acquisition clearly indicates that $\mathrm{Fe}^{3+}$ delivered to $P$. aeruginosa by citrate (via FecA since citrate-dependent Fe uptake and growth are compromised in a fecA mutant) must be reduced to $\mathrm{Fe}^{2+}$ prior to its transport into the cytosol. This explains the apparent lack of ferric citrate-specific cytoplasmic membrane transport components in $P$. aeruginosa and underscores a need for a reductive mechanism for release of $\mathrm{Fe}$ from citrate, presumably operational in the periplasm. The failure of two transposon mutant screens to identify a reductase as a component of citrate-mediated $\mathrm{Fe}$ acquisition in $P$. aeruginosa suggests that this component may be essential, though we cannot rule out that it was missed owing to inherent limitations of the screen itself. While periplasmic ferric citrate reductase activity has been reported in other organisms [L. pneumophila (Poch \& Johnson, 1993) and Vibrio vulnificus (Mazoy et al., 1999)], the only ferric citrate reductase activity reported to date in $P$. aeruginosa was found in the cytoplasm (Cox, 1980a). Assay conditions and/or sample preparation in this study may not, however, have been optimal for the proposed periplasmic reductase.

Citrate-promoted $\mathrm{Fe}$ acquisition has been demonstrated in H. pylori where it, too, is markedly reduced in a $f e o B$ mutant (Velayudhan et al., 2000), consistent with citrate ultimately providing $\mathrm{Fe}$ to $H$. pylori cells as $\mathrm{Fe}^{2+}$. In Leptospira biflexa, growth inhibition seen in Fe-limited medium was reportedly reversed by ferric citrate in wildtype cells but not $f e c A$ or $f e o B$ mutants, though no data were shown (Louvel et al., 2005). As in P. aeruginosa, this suggested that citrate-promoted Fe acquisition in L. biflexa proceeds via FecA and FeoB. Interestingly, L. biflexa also appears to lack $f e c B C D E$ homologues associated with ferric citrate uptake post-outer membrane.

A model whereby $\mathrm{Fe}$ is released from citrate in the periplasm is supported by the observation that additional loss of $p c o A$ in a $f e o B$ mutant fully compromised citratemediated $\mathrm{Fe}$ uptake, given the periplasmic ferroxidase activity of PcoA and its demonstrated involvement in $\mathrm{Fe}^{2+}$ acquisition in $P$. aeruginosa (Huston et al., 2002). Presumably, a reductive mechanism releases $\mathrm{Fe}$ from citrate and the resultant $\mathrm{Fe}^{2+}$ can then be transported via FeoB or oxidized to $\mathrm{Fe}^{3+}$ for transport via a cytoplasmic membrane $\mathrm{Fe}^{3+}$ transporter. That loss of the presumptive cytoplasmic membrane $\mathrm{Fe}^{3+}$ transporters PA5216-5217 and PA4687-4688 did not further compromise citratemediated $\mathrm{Fe}$ acquisition in a $f e o B$ mutant suggests that there must then be other systems for $\mathrm{Fe}^{3+}$ uptake across the cytoplasmic membrane. While FeoB and PcoA may be the major components for post-FecA transport of $\mathrm{Fe}$ delivered to cells by citrate, the observation that a $p c o A f e o B$ double mutant still demonstrated some citrate-dependent growth in Fe-restricted medium may be explained by an additional perhaps non-specific reductase activity that allows for sufficient $\mathrm{Fe}^{3+}$ for modest growth even though its transport was not detectable in a 15 min uptake assay. Certainly, loss of all four of FeoB, PcoA, PA5216-5217 and PA4687-4688 completely abrogated citrate-dependent growth and, indeed, prevented growth in low-Fe minimal medium, where exogenous addition of pyoverdine was required (data not shown).

In contrast to results with citrate, loss of the $\mathrm{Fe}^{2+} / \mathrm{Fe}^{3+}$ transport genes had no adverse effect on pyoverdine- or ferrioxamine B-dependent growth of $P$. aeruginosa in $\mathrm{Fe}$ restricted medium. As such, either $\mathrm{Fe}$ is not released into the periplasm from these siderophores and/or siderophorespecific transporters function in the post-outer-membrane receptor delivery of $\mathrm{Fe}$ provided by these siderophores. A cytoplasmic-membrane-associated ferrioxamine B transporter, FoxB, has, in fact, been described in $P$. aeruginosa (Cuiv et al., 2007). While there are a few candidate genes for cytoplasmic membrane ferric pyoverdine transporters, mutations in these do not compromise pyoverdinemediated $\mathrm{Fe}$ acquisition (Ochsner et al., 2002; Ravel \& Cornelis, 2003) and, indeed, several studies indicate that $\mathrm{Fe}$ delivered to $P$. aeruginosa via pyoverdine, as with citrate, is released in the periplasm (Greenwald et al., 2007; Mielczarek et al., 1990; Royt, 1990) via a reductive mechanism (Greenwald et al., 2007; Royt, 1990). Still, the observation that mutants lacking $\mathrm{FeoB}$ or, indeed, all of the other presumptive post-outer-membrane $\mathrm{Fe}$ transporters are competent for pyoverdine-promoted Fe acquisition suggests that Fe released from pyoverdine is probably transported via components specific for the pyoverdine system.

In conclusion, the results of this study confirm the involvement of the outer-membrane FecA receptor and 
the cytoplasmic membrane $\mathrm{FeoB} \mathrm{Fe}^{2+}$ transporter in citrate-mediated Fe uptake in $P$. aeruginosa. This system may serve as a model for Fe uptake promoted by heterologous siderophores in cases where siderophorespecific outer-membrane receptor genes are known but genes for siderophore-specific post-outer-membrane transport are lacking.

\section{ACKNOWLEDGEMENTS}

The authors thank V. Braun for providing polyclonal antiserum to $E$. coli FecA and Christelle Gruffaz for technical assistance. This was work supported by operating grants from the Canadian Institutes of Health Research (to K. P. and to A.S.).

\section{REFERENCES}

Adhikari, P., Berish, S. A., Nowalk, A. J., Veraldi, K. L., Morse, S. A. \& Mietzner, T. A. (1996). The $f b p A B C$ locus of Neisseria gonorrhoeae functions in the periplasm-to-cytosol transport of iron. J Bacteriol 178, 2145-2149.

Angerer, A., Klupp, B. \& Braun, V. (1992). Iron transport systems of Serratia marcescens. J Bacteriol 174, 1378-1387.

Ankenbauer, R. G. \& Cox, C. D. (1988). Isolation and characterization of Pseudomonas aeruginosa mutants requiring salicylic acid for pyochelin biosynthesis. J Bacteriol 170, 5364-5367.

Ankenbauer, R. G., Toyokuni, T., Staley, A., Rinehart, K. L., Jr \& Cox, C. D. (1988). Synthesis and biological activity of pyochelin, a siderophore of Pseudomonas aeruginosa. J Bacteriol 170, 5344-5351.

Ausubel, F. M., Brent, R., Kingston, R. E., Moore, D. D., Seidman, J. G., Smith, J. A. \& Struhl, K. (1992). Short Protocols in Molecular Biology, 2nd edn. New York: Wiley.

Banin, E., Vasil, M. L. \& Greenberg, E. P. (2005). Iron and Pseudomonas aeruginosa biofilm formation. Proc Natl Acad Sci U S A 102, 11076-11081.

Barcak, G. J., Chandler, M. S., Redfield, R. J. \& Tomb, J. F. (1991). Genetic systems in Haemophilus influenzae. Methods Enzymol 204, 321-342.

Braun, V. (2003). Iron uptake by Escherichia coli. Front Biosci 8, s1409-s1421.

Braun, V. \& Mahren, S. (2005). Transmembrane transcriptional control (surface signalling) of the Escherichia coli Fec type. FEMS Microbiol Rev 29, 673-684.

Braun, V., Mahren, S. \& Sauter, A. (2006). Gene regulation by transmembrane signaling. Biometals 19, 103-113.

Cao, L., Srikumar, R. \& Poole, K. (2004). MexAB-OprM hyperexpression in NalC type multidrug resistant Pseudomonas aeruginosa: identification and characterization of the nalC gene encoding a repressor of PA3720-PA3719. Mol Microbiol 53, 1423-1436.

Chamnongpol, S. \& Groisman, E. A. (2002). $\mathrm{Mg}^{2+}$ homeostasis and avoidance of metal toxicity. Mol Microbiol 44, 561-571.

Choi, K. H., Kumar, A. \& Schweizer, H. P. (2005). A 10-min method for preparation of highly electrocompetent Pseudomonas aeruginosa cells: application for DNA fragment transfer between chromosomes and plasmid transformation. J Microbiol Methods 64, 391-397.

Cornelis, P., Moguilevsky, N., Jacques, J. F. \& Masson, P. L. (1987). Study of the siderophores and receptors in different clinical isolates of Pseudomonas aeruginosa. Antibiot Chemother 39, 290-306.

Cox, C. D. (1980a). Iron reductases from Pseudomonas aeruginosa. J Bacteriol 141, 199-204.
Cox, C. D. (1980b). Iron uptake with ferripyochelin and ferric citrate by Pseudomonas aeruginosa. J Bacteriol 142, 581-587.

Cuiv, P. O., Clarke, P. \& O'Connell, M. (2006). Identification and characterization of an iron-regulated gene, $\operatorname{cht} A$, required for the utilization of the xenosiderophores aerobactin, rhizobactin 1021 and schizokinen by Pseudomonas aeruginosa. Microbiology 152, 945-954.

Cuiv, P. O., Keogh, D., Clarke, P. \& O'Connell, M. (2007). FoxB of Pseudomonas aeruginosa functions in the utilization of the xenosiderophores ferrichrome, ferrioxamine B, and schizokinen: evidence for transport redundancy at the inner membrane. J Bacteriol 189, 284287.

de Lorenzo, V., Herrero, M., Jakubzik, U. \& Timmis, K. N. (1990). Mini-Tn5 transposon derivatives for insertion mutagenesis, promoter probing, and chromosomal insertion of cloned DNA in Gramnegative eubacteria. J Bacteriol 172, 6568-6572.

Faguy, D. M., Bayley, D. P., Kostyukova, A. S., Thomas, N. A. \& Jarrell, K. F. (1996). Isolation and characterization of flagella and flagellin proteins from the thermoacidophilic archaea Thermoplasma volcanium and Sulfolobus shibatae. J Bacteriol 178, 902-905.

Ghysels, B., Ochsner, U., Mollman, U., Heinisch, L., Vasil, M., Cornelis, P. \& Matthijs, S. (2005). The Pseudomonas aeruginosa pirA gene encodes a second receptor for ferrienterobactin and synthetic catecholate analogues. FEMS Microbiol Lett 246, 167-174.

Greenwald, J., Hoegy, F., Nader, M., Journet, L., Mislin, G. L., Graumann, P. L. \& Schalk, I. J. (2007). Real time fluorescent resonance energy transfer visualization of ferric pyoverdine uptake in Pseudomonas aeruginosa. A role for ferrous iron. J Biol Chem 282, 2987-2995.

Hantke, K. (1987). Ferrous iron transport mutants in Escherichia coli K-12. FEMS Microbiol Lett 44, 53-58.

Harding, R. A. \& Royt, P. W. (1990). Acquisition of iron from citrate by Pseudomonas aeruginosa. J Gen Microbiol 136, 1859-1867.

Heinrichs, D. E., Young, L. \& Poole, K. (1991). Pyochelin-mediated iron transport in Pseudomonas aeruginosa: involvement of a highmolecular-mass outer membrane protein. Infect Immun 59, 36803684.

Hoang, T. T., Karkhoff-Schweizer, R. R., Kutchma, A. J. \& Schweizer, H. P. (1998). A broad-host-range Flp-FRT recombination system for site-specific excision of chromosomally-located DNA sequences: application for isolation of unmarked Pseudomonas aeruginosa mutants. Gene 212, 77-86.

Huston, W. M., Jennings, M. P. \& McEwan, A. G. (2002). The multicopper oxidase of Pseudomonas aeruginosa is a ferroxidase with a central role in iron acquisition. Mol Microbiol 45, 1741-1750.

Inoue, H., Nojima, H. \& Okayama, H. (1990). High efficiency transformation of Escherichia coli with plasmids. Gene 96, 23-28.

Kammler, M., Schon, C. \& Hantke, K. (1993). Characterization of the ferrous iron uptake system of Escherichia coli. J Bacteriol 175, 62126219.

Katoh, H., Hagino, N., Grossman, A. R. \& Ogawa, T. (2001). Genes essential to iron transport in the cyanobacterium Synechocystis sp. strain PCC 6803. J Bacteriol 183, 2779-2784.

Keen, N. T., Tamaki, S., Kobayashi, D. \& Trollinger, D. (1988). Improved broad-host-range plasmids for DNA cloning in Gramnegative bacteria. Gene 70, 191-197.

Llamas, M. A., Sparrius, M., Kloet, R., Jimenez, C. R., Vandenbroucke-Grauls, C. \& Bitter, W. (2006). The heterologous siderophores ferrioxamine $\mathrm{B}$ and ferrichrome activate signaling pathways in Pseudomonas aeruginosa. J Bacteriol 188, 1882-1891.

Llamas, M. A., Mooij, M. J., Sparrius, M., Vandenbroucke-Grauls, C. M., Ratledge, C. \& Bitter, W. (2008). Characterization of five novel 
Pseudomonas aeruginosa cell-surface signalling systems. Mol Microbiol 67, 458-472.

Louvel, H., Saint, G. I. \& Picardeau, M. (2005). Isolation and characterization of FecA- and FeoB-mediated iron acquisition systems of the spirochete Leptospira biflexa by random insertional mutagenesis. J Bacteriol 187, 3249-3254.

Mazoy, R., Lopez, E. M., Fouz, B., Amaro, C. \& Lemos, M. L. (1999). Ferric-reductase activities in Vibrio vulnificus biotypes 1 and 2. FEMS Microbiol Lett 172, 205-211.

Meyer, J. M. (1992). Exogenous siderophore-mediated iron uptake in Pseudomonas aeruginosa: possible involvement of porin OprF in iron translocation. J Gen Microbiol 138, 951-958.

Meyer, J.-M. \& Abdallah, M. A. (1978). The fluorescent pigment of Pseudomonas fluorescens: biosynthesis, purification and physiochemical properties. J Gen Microbiol 107, 319-328.

Meyer, J.-M. \& Hornsperger, J. M. (1978). Role of pyoverdine $\mathrm{Pf}_{\mathrm{P}}$ the iron-binding fluorescent pigment of Pseudomonas fluorescens, in iron transport. J Gen Microbiol 107, 329-331.

Meyer, J. M., Stintzi, A., Coulanges, V., Shivaji, S., Voss, J. A., Taraz, K. \& Budzikiewicz, H. (1998). Siderotyping of fluorescent pseudomonads: characterization of pyoverdines of Pseudomonas fluorescens and Pseudomonas putida strains from Antarctica. Microbiology 144, 3119-3126.

Meyer, J. M., Stintzi, A. \& Poole, K. (1999). The ferripyoverdine receptor FpvA of Pseudomonas aeruginosa PAO1 recognizes the ferripyoverdines of Pseudomonas aeruginosa PAO1 and Pseudomonas fluorescens ATCC 13525. FEMS Microbiol Lett 170, 145-150.

Michel, L., Bachelard, A. \& Reimmann, C. (2007). Ferripyochelin uptake genes are involved in pyochelin-mediated signalling in Pseudomonas aeruginosa. Microbiology 153, 1508-1518.

Mielczarek, E. V., Royt, P. W. \& Toth-Allen, J. (1990). A Mossbauer spectroscopy study of cellular acquisition of iron from pyoverdine by Pseudomonas aeruginosa. Biol Met 3, 34-38.

Miller, V. L. \& Mekalanos, J. J. (1988). A novel suicide vector and its use in construction of insertion mutations: osmoregulation of outer membrane proteins and virulence determinants in Vibrio cholerae requires toxR. J Bacteriol 170, 2575-2583.

Naikare, H., Palyada, K., Panciera, R., Marlow, D. \& Stintzi, A. (2006). Major role for FeoB in Campylobacter jejuni ferrous iron acquisition, gut colonization, and intracellular survival. Infect Immun 74, 54335444.

Nehme, D., Li, X. Z., Elliot, R. \& Poole, K. (2004). Assembly of the MexAB-OprM multidrug efflux system of Pseudomonas aeruginosa: identification and characterization of mutations in mexA compromising MexA multimerization and interaction with MexB. J Bacteriol 186, 2973-2983.

Ochsner, U. A., Wilderman, P. J., Vasil, A. I. \& Vasil, M. L. (2002). GeneChip ${ }^{\mathbb{R}}$ expression analysis of the iron starvation response in Pseudomonas aeruginosa: identification of novel pyoverdine biosynthesis genes. Mol Microbiol 45, 1277-1287.

Poch, M. T. \& Johnson, W. (1993). Ferric reductases of Legionella pneumophila. Biometals 6, 107-114.

Poole, K. \& McKay, G. A. (2003). Iron acquisition and its control in Pseudomonas aeruginosa: many roads lead to Rome. Front Biosci 8, d661-d686.

Poole, K., Young, L. \& Neshat, S. (1990). Enterobactin-mediated iron transport in Pseudomonas aeruginosa. J Bacteriol 172, 6991-6996.

Poole, K., Neshat, S. \& Heinrichs, D. (1991). Pyoverdine-mediated iron transport in Pseudomonas aeruginosa: involvement of a high- molecular-mass outer membrane protein. FEMS Microbiol Lett 62, $1-5$.

Ravel, J. \& Cornelis, P. (2003). Genomics of pyoverdine-mediated iron uptake in pseudomonads. Trends Microbiol 11, 195-200.

Redly, G. A. \& Poole, K. (2003). Pyoverdine-mediated regulation of FpvA synthesis in Pseudomonas aeruginosa: involvement of a probable extracytoplasmic-function sigma factor, FpvI. J Bacteriol 185, 12611265.

Robey, M. \& Cianciotto, N. P. (2002). Legionella pneumophila feoAB promotes ferrous iron uptake and intracellular infection. Infect Immun 70, 5659-5669.

Royt, P. W. (1990). Pyoverdine-mediated iron transport. Fate of iron and ligand in Pseudomonas aeruginosa. Biol Met 3, 28-33.

Sambrook, J. \& Russell, D. W. (2001). Molecular Cloning: a Laboratory Manual, 3rd edn. Cold Spring Harbor, NY: Cold Spring Harbor Laboratory.

Sanders, J. D., Cope, L. D. \& Hansen, E. J. (1994). Identification of a locus involved in the utilization of iron by Haemophilus influenzae. Infect Immun 62, 4515-4525.

Schäfer, A., Tauch, A., Jäger, W., Kalinowski, J., Thierbach, G. \& Pühler, A. (1994). Small mobilizable multi-purpose cloning vectors derived from the Escherichia coli plasmids pK18 and pK19: selection of defined deletions in the chromosome of Corynebacterium glutamicum. Gene 145, 69-73.

Schweizer, H. P. (1991). Escherichia-Pseudomonas shuttle vectors derived from pUC18/19. Gene 97, 109-121.

Simon, R., Priefer, U. \& Puehler, A. (1983). A broad host range mobilization system for in vivo genetic engineering: transposon mutagenesis in Gram-negative bacteria. Bio/Technology 1, 784-791.

Sobel, M. L., McKay, G. A. \& Poole, K. (2003). Contribution of the MexXY multidrug transporter to aminoglycoside resistance in Pseudomonas aeruginosa clinical isolates. Antimicrob Agents Chemother 47, 3202-3207.

Sobel, M. L., Poole, K. \& Neshat, S. (2005). Mutations in PA2491 (mexS) promote MexT-dependent mexEF-oprN expression and multidrug resistance in a clinical strain of Pseudomonas aeruginosa. J Bacteriol 187, 1246-1253.

Srikumar, R., Kon, T., Gotoh, N. \& Poole, K. (1998). Expression of Pseudomonas aeruginosa multidrug efflux pumps MexA-MexB-OprM and MexC-MexD-OprJ in a multidrug-sensitive Escherichia coli strain. Antimicrob Agents Chemother 42, 65-71.

Stover, C. K., Pham, X. Q., Erwin, A. L., Mizoguchi, S. D., Warrener, P., Hickey, M. J., Brinkman, F. S., Hufnagle, W. O., Kowalik, D. J. \& other authors (2000). Complete genome sequence of Pseudomonas aeruginosa PAO1, an opportunistic pathogen. Nature 406, 959-964.

Velayudhan, J., Hughes, N. J., McColm, A. A., Bagshaw, J., Clayton, C. L., Andrews, S. C. \& Kelly, D. J. (2000). Iron acquisition and virulence in Helicobacter pylori: a major role for FeoB, a high-affinity ferrous iron transporter. Mol Microbiol 37, 274-286.

Visca, P., Leoni, L., Wilson, M. J. \& Lamont, I. L. (2002). Iron transport and regulation, cell signalling and genomics: lessons from Escherichia coli and Pseudomonas. Mol Microbiol 45, 1177-1190.

Visca, P., Imperi, F. \& Lamont, I. L. (2007). Pyoverdine siderophores: from biogenesis to biosignificance. Trends Microbiol 15, 22-30.

Wyckoff, E. E., Mey, A. R., Leimbach, A., Fisher, C. F. \& Payne, S. M. (2006). Characterization of ferric and ferrous iron transport systems in Vibrio cholerae. J Bacteriol 188, 6515-6523.

Edited by: P. Cornelis 